\title{
The Analysis of Plyometric Training Program on University Handball Players
}

\author{
Professor Pramjeet Singh Ghuman, Dr. Harbans Lal Godara \\ Head \& Professor Department of Physical Education University of Rajasthan, Jaipur Rajasthan. \\ TGT Physical \& Health Education Kendriya Vidyalaya Sangthan Kendriya Vidyalaya STPS Suratgarh, \\ Rajasthan
}

\begin{abstract}
The purpose of this study was to find out the efficiency of composed plyometric training program on beginners Handball players force capabilities in their usual training period. The plyometric training program was applied during 16 week period where was attended twenty-one 12-19 years old beginners Handball players. Twelve of them were female and nine male handball players. There were three control tastings. All subjects participated in following tests: standing long jump, depth leap long jump, medicine ball throws up in 10 seconds; medicine ball overhead throws forward against the wall in 10 seconds, maximal vertical jumps to the maximal height in 10 seconds, maximal vertical jump height. Testing results statistical analysis has shown athletes legs and arms speed force reliable improvement. Standing long jump, depth leap long jump and maximal vertical jump height test results, what has shown legs explosive power, has not shown remarkable reliable difference $(P>0.05)$. Medicine ball throws and maximal vertical jumps to the maximal height in 10 seconds, what show speed force improvement, showed reliable difference $(P<0.01)$.
\end{abstract}

Key words: TRAINING METHOD, LEGS AND ARMS SPEED FORCE TRAINING.

\section{Introduction}

Modern handball requires for player a good physical endurance, parallel it is very important to develop speed and explosive power and force endurance. Handball is also a social game, where next to the good coordination and cleverness comes up to the important place team players good rapprochement and cooperation (Järvekülg, 2002).

Vertical jump ability is critical for success in handball. Jumping is utilized during the jump shut, jump attack from attack line, blocking and defending the opponent. A successful player must not only be able to jump high but must also be able to reach that height quickly. This requires an ability to generate power in a very short time (Powers, 1996). The use of strength during the play is determined by the fact that the usage of maximum strength lasts from 0.5 to 0.7 seconds; however, most of the explosive moments take substantially less time. For this reason the optimal usage and transformation of the gained maximum muscle strength into the "explosivity" of the main muscle group of the lower limbs, which take part in the takeoff, require special power training (Lehnert et al., 2009). Plyometric exercises have been shown to improve jump performance in many sports. These exercises combine strength with speed of movement to produce power. By using the myotatic stretch reflex of the muscle to produce an explosive reaction, plyometric is believed to be the link between speed and strength (Powers, 1996). The plyometric method is ranked among the most frequently used methods for conditioning in handball (Lehnert et al., 2009).

This research provides an overview of 16 weeks of plyometric training period which was attended by University of Rajasthan, Jaipur twenty-one university handball players. All players participated in testing measurements (Beginning of the program, four weeks later and end of the program).

Literature review has shown that in the world has made a lot of researches for plyometric method effectiveness and a little bit less researches about plyometric method efficiency for athletes. Most researches main point was to improve and investigate plyometric training effect for the legs. In this research we include also plyometric training effect for the arms. Previous studies handle mostly explosive power improvement. As a novelty in this research is that in the players testing has used the temporal parameters, which has not been observed in previous studies and what will make possible to investigate plyometric training effect to improve speed force. Jalak has defined speed force subsequently: Speed force represents nerve - muscle machine's ability to move the maximum speed of the whole body, body parts (hands, feet, etc.) or equipment (ball, disc, etc.) (Jalak, 2008). The purpose of this study was to find out the efficiency of composed plyometric training program on handball players force capabilities in their usual training period.

\section{Material And Methods}

Plyometric training should progress gradually from lower intensity to higher intensity drills, especially for individuals who lack a significant strength training background. 
Table 1. Intensity of various plyometric exercises.

\begin{tabular}{|c|c|}
\hline Exercise Type & Intensity \\
\hline Depth jumps 32- 48 in $(80-120 \mathrm{~cm})$ & High \\
\hline Bounding Exercises & Sub maximum \\
\hline Depth jumps 8- 20in $(20-50 \mathrm{~cm})$ & Moderate \\
\hline Low impact jumps/throws & Low \\
\hline
\end{tabular}

Depth jumps have a very powerful training effect so the volume of work should be low, no more than 4 sets of 10 repetitions, 2-3 times per week for advanced athletes and 3 sets of 5-8 repetitions, 1-2 times per week for lower classes of athletes (Baggett, 1995). A two- or three-day rest (48 hour minimum) between sessions will allow full recovery of the musculoskeletal system and further enhance adaptation. The number of repetitions and sets vary depending upon the intensity of the drill. As a rule, a low intensity exercise requires more repetitions. An exercise with a higher degree of difficulty requires fewer repetitions (Brittenham, 1995).

\section{The sample of subjects}

The plyometric training program was applied during 16 week period where was attended twenty-one University of Rajasthan, Jaipur university handball players. Their mean ( \pm SD1) age, height and mass were 15.5 \pm 2.03 years, $173.9 \pm 9.7 \mathrm{~cm}$ and $65.3 \pm 10.34 \mathrm{~kg}$, respectively. Twelve of them were female and nine male handball players (the players/gender characteristics are given in Table 2). They all had four practical trainings and two gym workout trainings sessions a week, and the sessions lasted 60 to 90 minutes. The plyometric exercises were practiced twice a week (Monday and Wednesday) after warming-up, the resting period between exercises series was one minute.

Table 2. Descriptive data of the player's characteristics

\begin{tabular}{||c|c|l|c|}
\hline & Age (y) & Height (cm) & Weight (kg) \\
\hline Female & $14.4 \pm 1.80$ & $167.8 \pm 6.97$ & $59.0 \pm 8.85$ \\
\hline Male & $17.0 \pm 1.25$ & $182.0 \pm 6.32$ & $73.7 \pm 4.71$ \\
\hline
\end{tabular}

\section{Results}

Although there were changes in all measured tests, explosive power parameters have not shown remarkable reliable improvement during this research. Standing long jump girl's group average changed from $194.8 \pm 13.2 \mathrm{~cm}$ to $203.3 \pm 13.2 \mathrm{~cm}(\mathrm{P}>0.05)$ and boys results average improvement was $240.9 \pm 16.7 \mathrm{~cm}$ to $248 \pm 15.5 \mathrm{~cm}(\mathrm{P}>0.05)$. Depth leap long jump girl's group average developed from $185.3 \pm 14.7 \mathrm{~cm}$ to $193.8 \pm$ $13.6 \mathrm{~cm}(\mathrm{P}>0.05)$ and boys results average changed from $238.3 \pm 17 \mathrm{~cm}$ to $246.4 \pm 17.7 \mathrm{~cm}(\mathrm{P}>0.05) \mathrm{In}$ maximal vertical jump height girl's group average was reliable improvement from $45.3 \pm 6.4 \mathrm{~cm}$ to $49.9 \pm 6.0$ $\mathrm{cm}(\mathrm{P}<0.05)$. Boys results changed from $62.1 \pm 5.9 \mathrm{~cm}$ to $67.2 \pm 6.3 \mathrm{~cm}(\mathrm{P}>0.05)$.

Speed force parameters have shown reliable improvement during this research. The program had a greater impact on the girl's group speed force development. Medicine ball throws and maximal vertical jumps to the maximal height test result, what show speed force improvement showed reliable difference. In medicine ball throws up in 10 seconds girl's group average improvement was $8.3 \pm 1.4$ times to $10.8 \pm 1.1$ times $(\mathrm{P}<0.001)$ and boys results average improvement was $10.1 \pm 1.7$ times to $12.1 \pm 1.1$ times in 10 seconds $(\mathrm{P}<0.01)$. In maximal vertical jumps to the maximal height in 10 seconds girl's group average improvement was $4.1 \pm 1.0$ times to $5.8 \pm 1.2$ times $(\mathrm{P}<0.001)$ and boys results average improvement was $4.3 \pm 0.5$ times to $6.6 \pm$ 0.5 times in 10 seconds $(\mathrm{P}<0.0001)$.

\section{Discussion}

In the discussion section of the statistical analysis, what can be noted is that the use of the set of plyometric exercises has shown athletes legs and arms speed force improvement, but explosive power parameters has not shown remarkable reliable difference. Standing long jump, depth leap long jump and maximal vertical jump height test results, what has shown legs explosive power, were not reliably different. Medicine ball throws and maximal vertical jumps to the maximal height in 10 seconds, which demonstrate speed force abilities, showed reliable difference. A considerable increase in the jumping and throwing skills was found among the members of the experimental group, and so it is more justified to use this type of plyometric exercises to improve speed force skills than explosive power.

Standing long jump and depth leap long jump results statistical analysis shows that girls and boys group T-test results did not show reliable difference in the average results $(\mathrm{P}>0.05)$. Depth leap long jump results are smaller. This is expected result, because it can be assumed that depth leap long jump technique was 
new for athletes and was hard to adjust quickly to the new technique.

Medicine ball throws up and medicine ball overhead throws forward against the wall test results showed arms muscle speed force improvement. In medicine ball throws up in girls group got an improvement 2.6 times $(30.1 \%)$ and boy's 2 times $(19.8 \%)$. Girls and boys group average comparison of the test results showed that in this assay were reliable differences $(\mathrm{P}<0.01)$. Medicine ball overhead throws forward against the wall test result got improvement in female group 2, 3 times (25.6\%) and in male group 1, 7 times (14.9\%). Both group average comparison of the test results showed that in this assay were reliable differences $(\mathrm{P}<0.01)$. The noted difference occurs under the influence of the applied experimental factor, by means of which we can conclude that the used experimental program of plyometric training had a positive effect on the transformation of arms speed force of the subjects. Girls group got better improvement than boys. It can be assumed that girl's group got better improvement is due to the fact that girl arms elementary speed force was lower.

\section{Procedures}

The players had four trainings per week, and two of them had included plyometric training. Training duration was 90 minutes. Prior to each training session, all subjects participated in a 10 minute warm-up period which included jogging at a self-selected comfortable pace followed by calisthenics. After warming-up session players performed plyometric training and after finishing starts with their usual training. All athletes have got instructions how to make exercises correctly before starting plyometric program.

Table 3. Plyometric training exercises program.

\begin{tabular}{ccc} 
Day & Number & Exercise \\
\hline \multirow{2}{*}{ Monday } & $2 \times 10$ & Squat Jumps \\
& $2 \times 10$ & Lateral Box Push Offs \\
& $2 \times 15$ & Overhead Throws \\
& $2 \times 10$ & Split Squat Jumps \\
& $2 \times 15$ & Power Drop \\
& $2 \times 10$ & Depth Jumps \\
\hline Wednesday & $2 \times 10$ & Squat Jumps \\
& $2 \times 10$ & Lateral Hurdle Jumps \\
& $2 \times 15$ & Overhead Throws \\
& $2 \times 10$ & Split Squat Jumps \\
& $2 \times 8$ & Plyometric Push-Ups \\
\end{tabular}

Testing procedures

All players participated in three control testing. First measuring was before plyometric training session in July 2013. Second testing was after four weeks plyometric training streak in August 2013 and last control measuring has taken 16 weeks after first testing in October 2013.

1. Standing long jump.

2. Depth leap long jump.

3. Medicine ball throws up in 10 seconds.

4. Medicine ball overhead throws forward against the wall in 10 seconds.

5. Maximal vertical jumps to the maximal height in 10 seconds.

6. Maximal vertical jump height.

\section{Statistical Analyses}

Descriptive data were calculated for all variables. Group differences at baseline were evaluated using independent sample T-tests.

Whole athletes group shows $4.9 \mathrm{~cm}$ increase in maximum height of vertical jump which is similar for handball players to the shooting ball in goal post and blocking the ball during long jump shoot. This result numerically does not differ a lot from Milic et al. (2008) research result where three - foot block jump has increase $3.53 \mathrm{~cm}$. Analysing female and male groups separately we can see that female group result shows reliable difference $(\mathrm{P}<0.05)$, but male group result did not show reliable difference $(\mathrm{P}>0.05)$. It can be assumed that girl's group got better improvement is due to the fact that girl legs elementary explosive power was lower. Female group increase was $4.7 \mathrm{~cm}$ which result is similar to the Lehnert et al. (2009) research where maximal vertical jump has shown increase $4 \mathrm{~cm}$. Male group increase was $5.1 \mathrm{~cm}$ which result is similar to the Shaji and 
Isha (2009) research where maximal vertical jump has shown increase $4.8 \mathrm{~cm}$. Faigenbaum et al. (2007) got vertical jump increase in their research $3.4 \mathrm{~cm}$. It can be assumed that the difference between results is affected by the length of the experiment. Adams et al. (1992) research compared three training programs: Squat, plyometric and squat-plyometric. Examination of the mean scores shows that the squat group increased $3.30 \mathrm{~cm}$ in vertical jump, the plyometric group increased $3.81 \mathrm{~cm}$ and the squat-plyometric group increased $10.67 \mathrm{~cm}$. This research results indicate that combined training can be more effective than plyometric training alone.

In addition to the development of vertical jumping ability, we can see that in test results there is one important increase in maximal vertical jumps to the maximal height in 10 seconds which indicate speed force. This shows $46.5 \%$ increase for whole group, it is 1.95 times more than in first testing. Girls group got an improvement 1,8 times (41.5\%) and boy's group 2, 2 times (53.5\%). This is very important skill in handball, because a handball match can be played for two half, which means that the match can last about 70 (Seventy) minutes, during which time a player can perform 250-300 actions dominated by the explosive type strength of the leg muscles. Of the total number of actions, jumps take up around $50-60 \%$, high speed movements and changes of direction in space about $30 \%$ and falls about $15 \%$ (Stojanovic \& Kostic, 2002). T-test analysis showed that both group average indicators before and after the eksperiment had reliable differences $(\mathrm{P}<0.01)$. Based on this result we can conclude that plyometric exercises are effective tools for improving young handball player's ability to perform repeated maximal jumps at the maximum height.

There are general principles that apply to plyometric training regarding the muscular pattern of movement in the process of overcoming any strain, but each handball player requires an individual program. The vertical jump is an individual characteristic, and so one needs to select exercises and determine their intensity and extent accordingly. One of the significant conditions that come with using plyometric method, are the characteristics determined by the age of each individual handball player.

\section{Conclusions}

Based on results of the research we can conclude, that: explosive power parameters have not shown remarkable reliable improvement but speed force parameters have shown reliable improvement during this research. The program had a greater impact on the girl's group speed force development.

\section{References}

[1]. Adams K, O'Shea Jp, O'Shea K1, Climstein M. The effect of six weeks of squat, plyometric and squat-plyometric training on power production. Journal of Applied Sport Science Research. 1992; 6(1):36-41.

[2]. Arsac, LM, Belli, A, and Lacour, JR. Muscle function during brief maximal exercise: Accurate measurements on a friction - loaded cycle ergometer. Eur J Appl Physiol Occup Physiol 74: 100 - 106, 1996.

[3]. Avery D. Faigenbaum, James E. McFarland, Fred B. Keiper, William Tevlin, Nicholas A. Ratamess , Jie Kang and Jay R. Hoffman; Effects of a short-term plyometric and resistance training program on fitness performance in boys age 12 to 15 years; Journal of Sports Science and Medicine (2007) 6, 519-525

[4]. Behm, DG and Sale, DG. Velocity specificity of resistance training. Sports Med 15: 374- 388, 1993.

[5]. Chelly,MS, Fathloun, M, Cherif, N, Ben Amar, M, Tabka, Z, and Van Praagh, E. Effects of a back squat training program on leg power, jump- and sprint performances in junior soccer players. J Strength Cond Res 23: 2241-2249, 2009.

[6]. De Villarreal, ES, Kellis, E, Kraemer, WJ, and Izquierdo, M. Determining variables of plyometric training for improving vertical jump height performance: A meta-analysis. J Strength Cond Res 23: 495-506, 2009.

[7]. Faigenbaum Ad, Mcfarland Je, Keiper Fb, Tevlin W, Ratamess Na, Kang J, Hoffman Jr. Effects of a short-term plyometric and resistance training program on fitness performance in boys age 12 to 15 years. Journal of Sports Science and Medicine. 2007; 6:519-525.

[8]. Goran Markovic; Does plyometric training improve vertical jump height? A meta-analytical review; British Journal of Sports Medicine 2007;41, 349-355.

[9]. Goran Spori, Dinko Vuleta, Dinko Vuleta Jr. and Milanovi Dragan. Fitness Profiling in Handball: Physical and Physiological Characteristics of Elite Players. Coll. Antropol. 3: 34-2010.

[10]. Hermassi S, Chelly MS, Tabka Z, Shephard RJ, Chamari K. Effects of 8 -week in-season upper and lower limb heavy resistance training on the peak power, throwing velocity, and sprint performance of elite male handball players. J Strength Cond Res. 2011 Sep;25(9):2424-33.

[11]. Herrero, JA, Izquierdo, M, Maffiuletti, NA, and Garc'ra-Lo' pez, J. Electromyostimulation and plyometric training effects on jumping and sprint time. Int J Sports Med 27: 533-539, 2006.

[12]. Holcom, W.R., Lander J.E., Rutland R.M., and Wilson G.D. The effectiveness of a modified plyometric program on power and the vertical jump. J Strength Cond Res 10:89-92. 1996.

[13]. Jeffery F. Vossen., John F. Kramer, Darren G. Burke and Deborahp. Vossen. Comparison of Dynamic Push-Up Training and Plyometric Push-Up Training on Upper-Body Power and Strength. J Strength Cond Res. 2000, 14(3), $248-253$.

[14]. Kotzamanidis, C. Effect of plyometric training on running performance and vertical jumping in prepubertal boys. J Strength Cond Res 20: 441-445, 2006.

[15]. Lehnert M, Lamrova I, Elfmark M. Changes in speed and strength in female volleyball players during and after a plyometric training program. Acta Universitatis Palackianae Olomucensis Gymnica. 2009; 39(1):59-66

[16]. Markovic, G, Jukic, I, Milanovic, D, and Metikos, D. Effects of sprint and plyometric training on muscle function and athletic performance. J Strength Cond Res 21: 543-549, 2007.

[17]. Marques MC, González-Badillo JJ. In-season resistance training and detraining in professional team handball players. J Strength Cond Res. 2006 Aug;20(3):563-71.

[18]. Mero, A, Luhtanen, P, Viitasalo, JT, and Komi, PV. Relationships between the maximal running velocity, muscle fiber characteristics, force production and force relaxation of sprinter. Scand J Sports Sci 3: 16-22, 1981. 
[19]. Michael G. Miller, Jeremy J. Herniman, Mark D. Ricard, Christopher C. Cheatham And Timothy J. Michael; The effects of a 6week plyometric training program on agility; Journal of Sports Science and Medicine (2006) 5, 459-465.

[20]. Milic V, Ncjic D, Kostic R. The effect of plyometric training on the explosive strength of leg muscles of volleyball players on single foot and two-foot takeoff jumps. Physical Education and Sport. 2008; 6(2):169- 179

[21]. Moore, EW, Hickey,MS, and Reiser, RF. Comparison of two twelve week off-season combined training programs on entry level collegiate soccer players' performance. Jump Strength Cond Res 19: 791-798, 2005.

[22]. Pauole Kainoa; Madole Kent; Garhammer John; Lacourse Michael; Rozenek Ralph; reliability and validity of the t-test as a measure of agility, leg power, and leg speed in college-aged men and women; Journal of Strength \& Conditioning research ;2000, $14,443-450$

[23]. Pers J, Bon M, Kovacic S, Sibila M, and Dezman B. Observation and analysis of large-scale human motion. Hum Mov Sci 21: 295$311,2002$.

[24]. Shaji J, Isha S. Comparative analysis of plyometric training program and dynamic stretching on vertical jump and agility in male collegiate basketball player. Al Ameen J Med Sci. 2009; 2(1);36-46.

[25]. Sibila, M, Vuleta, D, and Pori, P. Position- related differences in volumes and intensity of large-scale cyclic movements of male players in handball. Kinesiology 36: 58-68, 2004.

[26]. Stojanovic T, Kostic R. The effects of the plyometric sport training model on the development of the vertical jump of volleyball players. Physical Education and Sport. 2002; 1(9):11 -25.

[27]. Vissing, K, Brink, M, Lønbro, S, Sørensen, H, Overgaard, K, Danborg, K, Mortensen, J, Elstrøm, O, Rosenhoj, N, Ringgaard, S, Andersen, JL, and Aagaard, P. Muscle adaptations to plyometric vs. resistance training in untrained young men. J Strength Cond Res 22: $1799-1810,2008$.

[28]. Wagner, DR and Kocak, MS. A multivariate approach to assessing anaerobic power following a plyometric training program. J Strength Cond Res 11: 251-255, 1997. 